Dialeges with the Ata ospheric Boundary Layer

Integrating physics, chemistry and biology

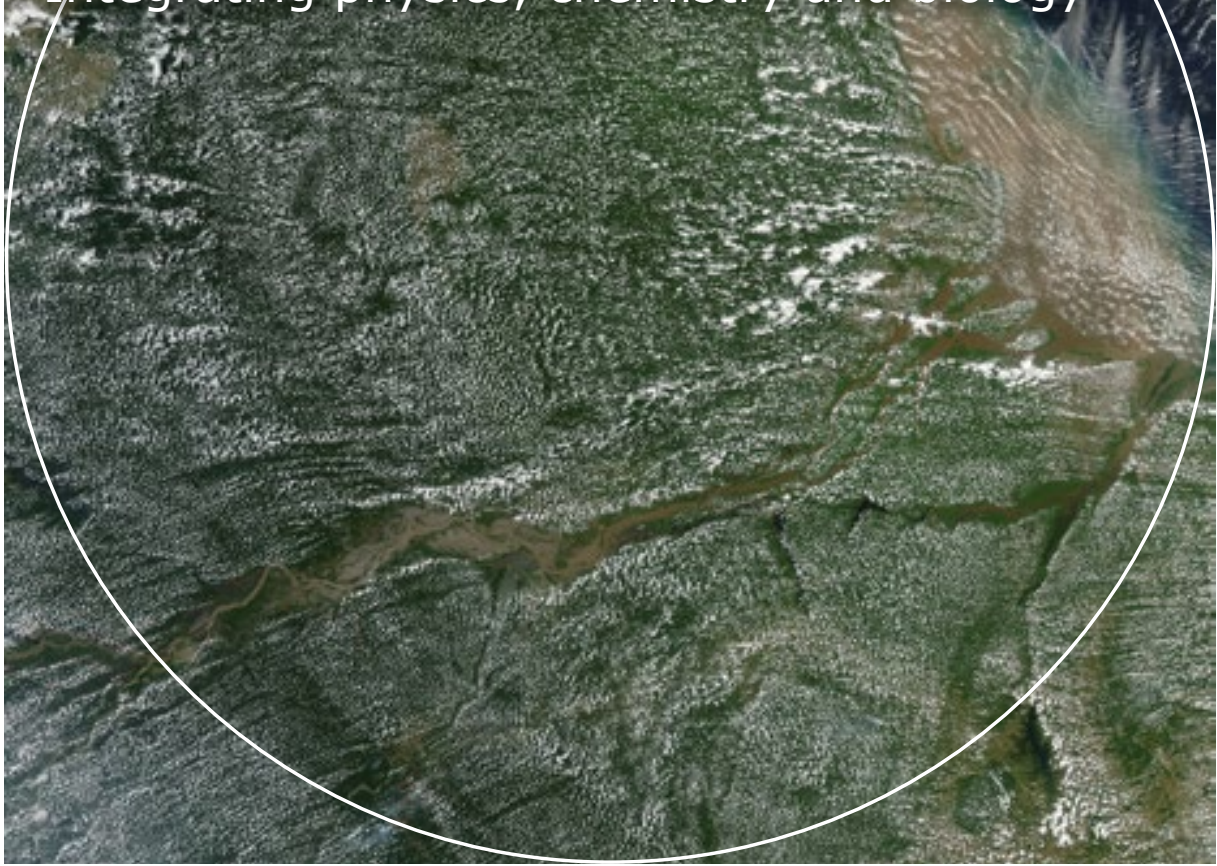

Prof.dr Jordi Vilà-Guerau de Arellano

Inaugural lecture upon taking up the position of Personal Professor of Environmental Sciences Group at Wageningen University \& Research on 13 April 2017 



\section{Dialogues with the atmospheric boundary layer integrating physics, chemistry and biology}

\section{Prof.dr Jordi Vilà-Guerau de Arellano}

Inaugural lecture upon taking up the position of Personal Professor of Environmental Scienceas Group at Wageningen University \& Research on 13 April 2017 
DOI HTTPS://DOI.ORG/10.18174/432701

ISBN 978-94-6343-880-3 


\section{Dialogues with the atmospheric boundary layer integrating physics, chemistry and biology}

Esteemed Rector Magnificus, dear colleagues, students, family and friends:

Let me start with my conclusions:

- When you breathe, you are breathing air from the atmospheric boundary layer. However, we don't yet fully understand how the air composition of the atmospheric boundary layer is changing.

- Your yesterday's salad, if tasty, probably grew under solar, temperature and water vapour conditions that depend on the atmospheric boundary layer dynamic changes, but we don't fully control how this growth occurs.

- Hopefully, the energy that lights and heats your house is extracted from wind turbulent kinetic energy generated in the atmospheric boundary layer. However, we are not yet completely efficient in extracting the maximum of this energy driven by atmospheric movements.

These are the raisons d'être of our investigations on the atmospheric boundary layer (Stull, 1988), all of which are closely related to physics (energy), chemistry (atmospheric composition) and biology (plant and soil) as Figure 1 shows.

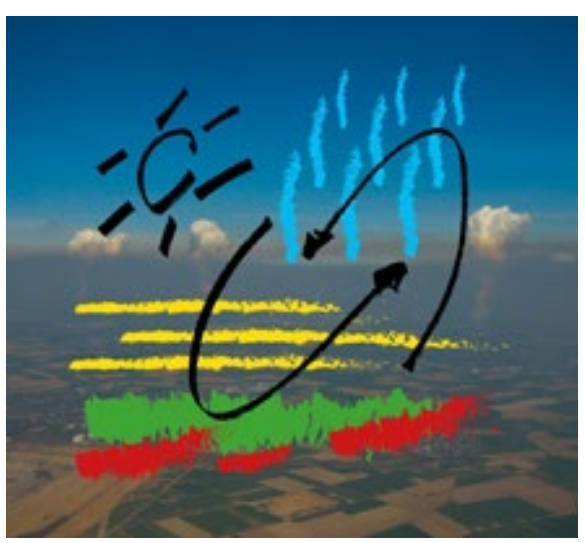

Figure 1. The background picture shows the atmospheric boundary layer: the atmospheric region in between the surface characterized by a mosaic of land uses and the free troposphere (the clean blue sky region at the image). The conceptual drawings represent: vegetation (green) and soil (red) processes, atmospheric composition variation (yellow), clouds (sky blue) and turbulence (black arrows), all these processes driven by the solar radiation. Courtesy and credit: Bart van Stratum. 
At this point, I could stop my lecture and we could all move to the drinks, but instead I would like to share with you four dialogues that have been very present in my thinking throughout my academic career. All of them are strongly rooted in the essential processes of studying, understanding and representing the atmospheric boundary layer as a whole.

\section{Dialogue 1: Specialization versus interdisciplinarity}

\section{Turbulence!}

This is the word that I have been desperately searching for to start this lecture. It brings the idea of confusion and chaos, fastening aircraft seatbelts in the rough atmospheric regions and relationships that are desirable but which can get you into trouble. But, What is the role of turbulence in the atmosphere and why is it important?

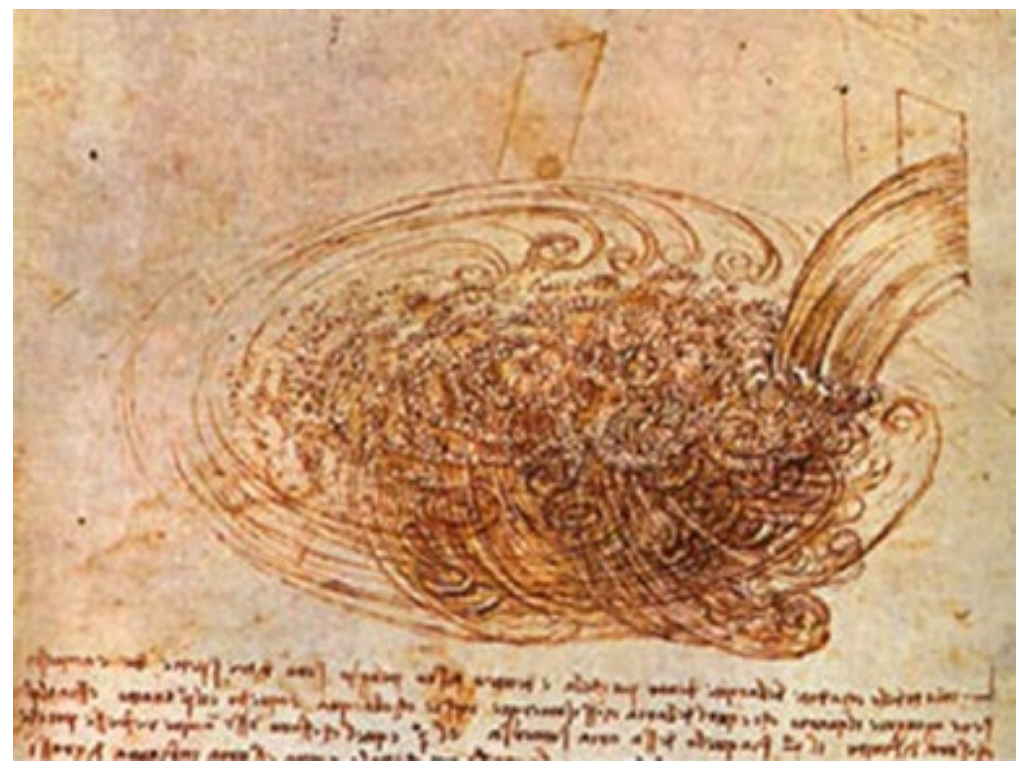

Figure 2. Study of water falling into still water by Leonardo Da Vinci (c. 1508-1509) from the Codex Atlanticus (Atlantic Codex) written and drawn in between 1478 and 1519. The drawing shows the differences between the streamline laminar flow (right) and the turbulent chaotic movement of the water flow (centre). 
Let's start this first dialogue by moving back some 500 years ago, to when Leonardo Da Vinci made one of the first ever scientific drawings (Da Vinci, 1519). Da Vinci was already able to distinguish that the water or air flow have different movement characteristics: from laminar and predictable to turbulent and chaotic. With an outstanding human anticipation of the course of events, prescience, he was able to depict two key aspects of the turbulent flows that are still in use today to characterise and to describe them (Figure 2): first, the recognition of eddies as an intrinsic characteristic of turbulent flow, and secondly the possibility of describing and predicting the mean characteristics of the flow, but, at the same time, the extreme limitations on our ability to calculate it and forecast the fluctuating and chaotic part. Unlike laminar flow, where we know with some certainty where the flow will move to, the unpredictable character of turbulent flow leads many scientists to continue to attempt to better understand the nature of turbulence and attempt to solve it. For physicists, this has become some sort of holy grail.

A key aspect of fully developed turbulence regimes is that they occupy and cohabit a wide range of coupled spatial and temporal scales. I will elaborate more on this aspect later on. In the atmospheric region touching the biosphere, what we call the atmospheric boundary layer, turbulence acts like a cascade, within which the most energetic eddies break down into smaller and smaller scales until they finally dissipate.

I have already mentioned the biosphere, the living component of the Earth system. Here, I meet my first dilemma, which is central to my first dialogue:

\section{Should I study turbulence as an isolated phenomenon?}

or

Should I attempt to relate turbulence to the processes that occur within the biosphere or to those in the upper regions of the atmosphere?

I could have selected the first path to focus on obtaining a fundamental understanding of turbulence as an isolated phenomenon by developing theories and confirming or refuting them through experimental observations or performing numerical simulations (only the black arrows in Figure 1). In doing so, I could have attempted to improve the understanding of how turbulence influences the weather and climate as an isolated key phenomenon.

Instead of selecting this scientific route, I chose to study the sources and sinks, most of them located within or above the biosphere, that provide the necessary energy to generate or dissipate turbulence and, in turn, to examine how turbulence becomes 
the main transporter of energy, water and matter from the biosphere into the rest of the atmosphere (all the processes interacting in Figure 1). Permit me to elaborate and justify the reasons for my selection.
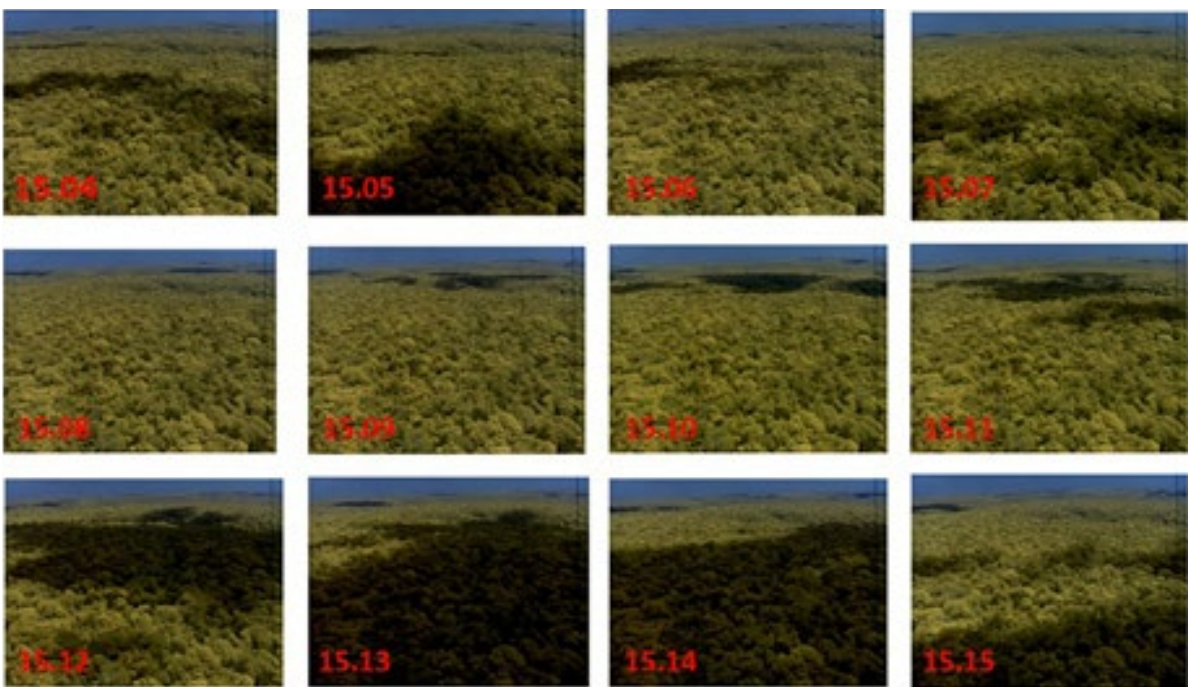

Figure 3. Twelve sequential images of the Amazonia rain forest taken during the dry season from the 325 metres Amazon Tall Tower Observatory (ATTO). The pictures were taken between 15.04 and 15.15 local time. The images show the continuous change in radiation over the forest which influence photosynthesis and plant transpiration, and therefore atmospheric turbulence and cloud formation. Courtesy and credit to Matthias Sörgel (Max Planck Institute Chemistry at Mainz, Germany).

Let us first move to the Amazonian tropical rainforest to better introduce it (Figure 3). It is early afternoon during the dry season, and it is hot and humid. Instead of enjoying a well-deserved siesta, we have climbed the 150-metres of the 325-metre ATTO (Amazon Tall Tower Observatory, http://www.mpic.de/en/research/ collaborative-projects/atto.html) (Andreae et al., 2015) tower built up by the Max Planck Institute for Chemistry and Biochemistry and the National Institute for Amazon Research (INPA).

The energy originating from the sun is used by the plants to photosynthesize and transpire, and the rest warms the top of the forest. As a result, the air just above becomes less dense and therefore starts to rise. The rising air transports not only heat, but also moisture, due to leaf transpiration, which we generally call evaporation, that is essential to the photosynthesis process. 
These upward movements lead to strong instabilities that produce turbulent thermals transporting heat and moisture. Under the right temperature and humidity conditions, moisture condensates at the top of the turbulent thermal and forms clouds. We might say that the turbulent thermals act similarly to plant roots, providing the necessary water vapour needed for cloud formation and intensification. This chain of connected processes does not end here. Let's have a look at how dynamic the system is!

As you can see from figure 3, the appearance of clouds perturbs the transfer of radiation and affects the photosynthesis. First, they shade vegetation, leading to reduction in photosynthesis activity, but at the same time clouds enhance diffuse radiation. Unlike direct radiation, diffuse radiation is not direction dependent, and it is more efficient at penetrating the canopy, and thus at facilitating photosynthesis. The overall result, characterized by both negative and positive effects, is a perturbation of the sources and sinks of energy, of water and of matter that locally influence turbulence and might thus jeopardize the further formation of clouds.

Let us explain in more detail this interactive process by starting from the biological perspective. Plants need their stomata to be open during the day in order to photosynthesise. The opening depends on atmospheric conditions regulated by light intensity, air temperature and the water vapour pressure deficit, but these conditions change very dynamically and are highly dependent on turbulence and radiation. During $\mathrm{CO}_{2}$ assimilation, plants transpire in such a way as to maintain the optimal conditions for $\mathrm{CO}_{2}$ uptake. In other words, the plants' motto is: maximum $\mathrm{CO}_{2}$ assimilation and minimum water loss. This leads to limits on evaporation, while the rest of the available energy is used to heat up the atmosphere. Both warming and evaporation are the key drivers in forming and regulating the intensity of turbulence. The coupling between life, as represented by plants, and the atmospheric dynamic state becomes a reality.

I have still to discuss a crucial component of this interactive system: chemistry. To complete my discussion of the complexity of the biosphere-atmosphere interaction, plants also emit biogenic volatile organic compounds. These compounds are molecules in which the atom carbons play an important role and have a strong tendency to evaporate. We don't yet fully understand why plants emit biogenic compounds. Possible reasons include the prevention of diseases or to communicate with each other. For us, as atmospheric scientists, the most important aspect is that after reacting chemically, these molecules become particles or aerosols which, if activated, form cloud droplets, a key component for the formation and intensification of clouds. 
To end my first dialogue, I take a clear position in studying turbulence in a holistic context into which the individual biological, chemical and physical components of the biosphere-atmosphere puzzle must be fitted and integrated if we wish to understand the entire system. This puzzle of processes involves biological, chemical and physical mechanisms acting on different scales.

\section{Dialogue 2: Isolating versus crossing}

How shall we study these interactions between the biosphere and the atmosphere? and

Where is the challenge?

Roughly speaking, a leaf stoma is half the diameter of a hair and the stomata occupy a total of only $1 \%$ of the leaf surface (Figure 4 ). It is through the stomata that plants assimilate $\mathrm{CO}_{2}$ and lose water to the atmosphere.

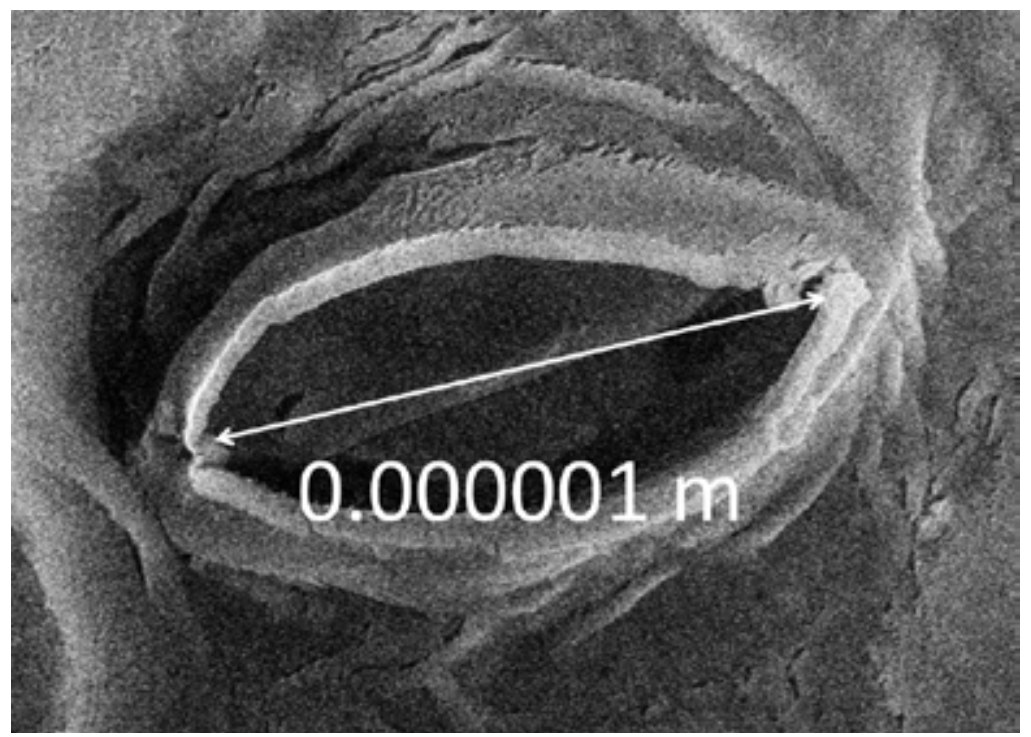

Figure 4. Electron micrograph of a stoma from a Brassica chinensis (Bok Choy) leaf. The image shows the characteristic length scale of the stoma by which the interchange of carbon dioxide (gained by the plant) and water vapour (gained by the atmosphere) between the leaf and the atmosphere occurs. (Source Wikipedia, Stoma). 
At the same time, clouds may well extend several kilometres vertically and occupy entire regions such as Amazonia with all sort of shapes and dynamic evolution (Figure 5). In other words, a large amount of the fuel (moisture) of clouds emanates from tiny openings in individual leaves.

As you can see from both pictures, there are huge differences on the size associated to connect land and atmosphere phenomena. To understand this interactive system characterized by a wide range of scales, we first need to have a well-defined research strategy in order to isolate the processes and attempt to understand them. Then, in a second stage, we can reconstruct the puzzle by fitting the individual blocks and study how the processes are interacting. In short, we study first in detail the separate components of the puzzle in order to subsequently systematically rebuild the puzzle again.

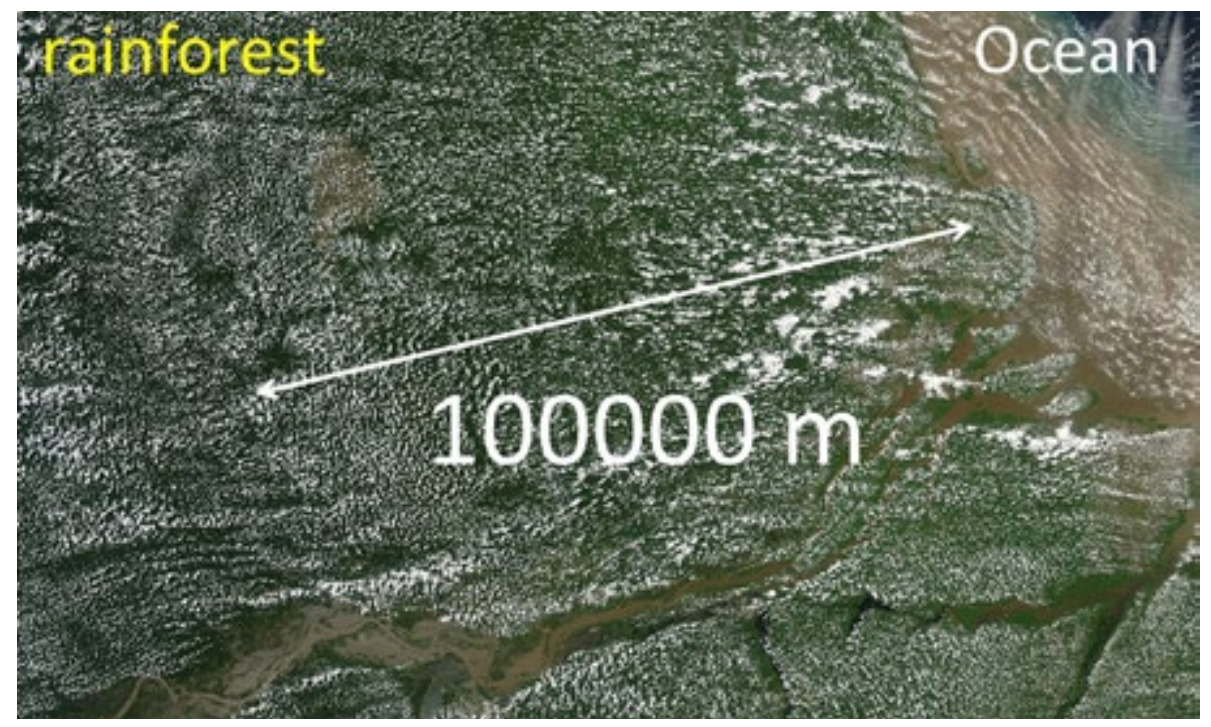

Figure 5. Image captured by the Moderate Resolution Imaging Spectroradiometer (MODIS) instrument on NASA's Aqua satellite showing the interaction between the Amazonia rainforest and the atmosphere as well as the representative length scale. The image shows the transition between the shallow cumulus (small clouds) to deep convective clouds, and the absence of clouds formed over the river. It was captured on August 19th 2009 (Source and credit : https://earthobservatory.nasa.gov/).

To organize the study of such a complex system, we introduce the concept of temporal and spatial scales. Allow me to present two key examples to show the need of these scales. 
We are interested in tomorrow's weather here in the Netherlands, or even better, in Wageningen itself. Since these scales are very close to us, I will call them daily and local scales. To study them we need models and measurements that provide us with spatial detail and that can be calculated rapidly: we need an accurate forecast in good time before things happen. In other words, the puzzle is made up of relatively small pieces, but with short integration times and limited area domain. All these conditions enable us to make timely forecasts.

However, we are also concerned about what the climate will be in 50 or 100 years time and the climate changes affecting the entire planet Earth. I will call these the climate and global scales. Now my puzzle is composed of much larger pieces, which are less reliable and accurate in the description of the small processes that occur within the grid, but which allow us to calculate long integration climate times. My second dialogue deals with this challenge:

\section{Should we stick with one spatial and temporal scale?}

or

\section{Should we attempt to cross these spatiotemporal scales?}

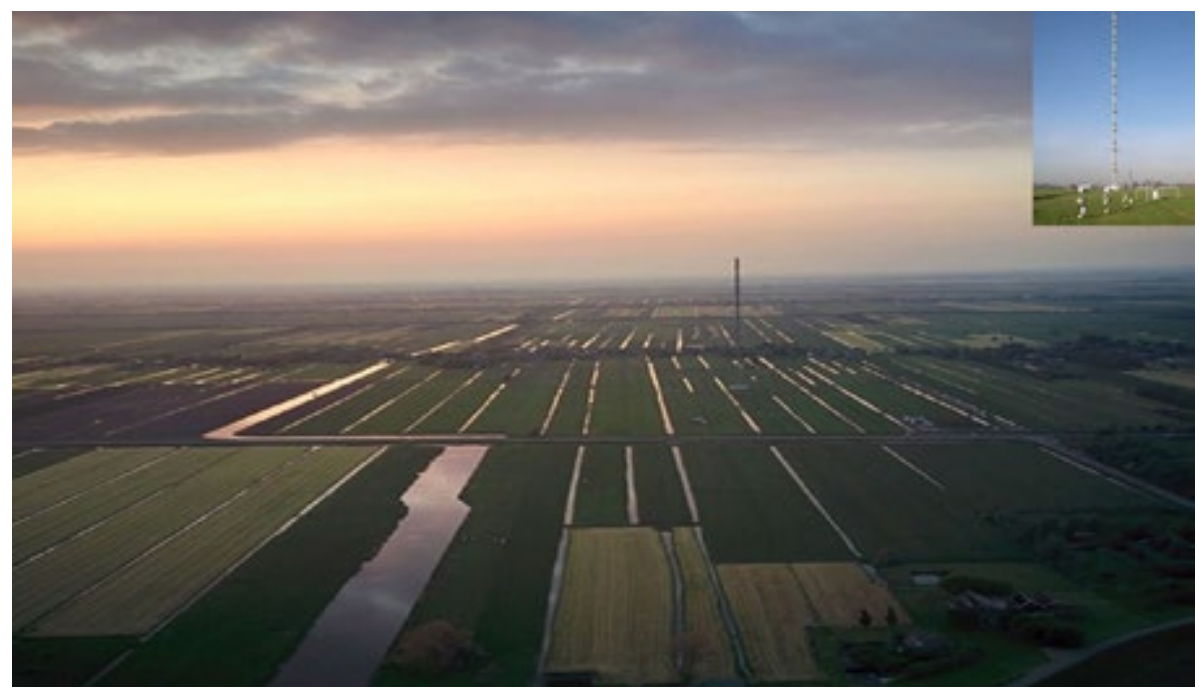

Figure 6. The 213-metre meteorological tower at Cabauw, the main platform of the CESAR consortium (http://www.cesar-observatory.nl/). It is located between the cities of Utrecht and Gouda, in the Western part of the Netherlands $\left(51.971^{\circ} \mathrm{N}, 4.927^{\circ} \mathrm{E}\right)$ in a polder region covered by grass and 0.7 metre above sea level. In addition to a complete set of meteorological and atmospheric composition observations at the tower and in the nearby surface, there are instruments using remote-sensing techniques like rain radar, and ceilometers. Courtesy and credit: Bert Heusinkveld. 
Let's move now to a Dutch Polder to get some answers, more specifically at Cabauw (a small village between IJsselstein and Gouda, close to the River De Lek), for a better framework for this dialogue.

It is sunset on a nice summer day in the Netherlands, and instead of drinking a beer at the Oude Gracht in Utrecht, we have decided to take some meteorological measurements, so we are suspended from a hot-air balloon looking at the unique CESAR 213-metre meteorological tower (Apituley et al., 2008), which has been in place for more than 40 years collecting hydrological, surface, meteorological, climatological and atmospheric chemistry data (Figure 6). These data are crucial to the process of fitting together the different parts of the biosphere-atmosphere puzzle. From our multiple observations at CESAR, I select a measurement of the atmospheric boundary layer depth to illustrate the richness, variability and complexity of the atmospheric layer that is in direct contact with the biosphere. Its depth quantifies the vertical extent of turbulence and its intensity.

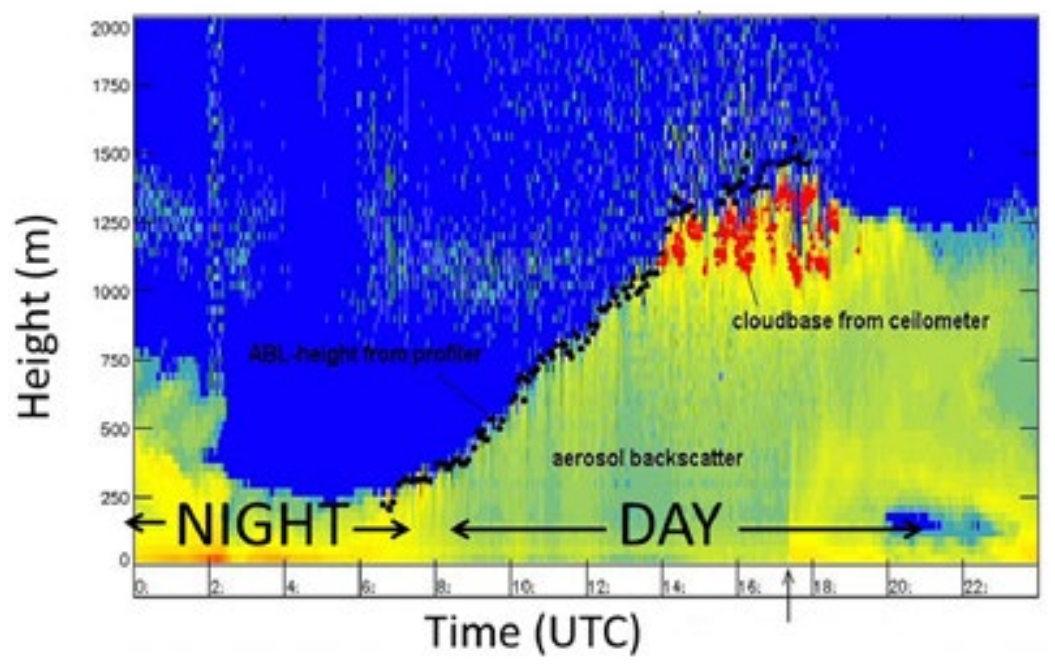

Figure 7. The boundary layer height evolution (black dots) measured by a wind profiler in a typical summer day (27th July 2002) in the Netherlands at Cabauw. The two prototypical atmospheric boundary layers are clearly defined: night or stable boundary layer (from 0 until 7 UTC) and day or convective boundary layer (from 7 UTC until 18 UTC). The red dots indicate the cloud base, probably shallow cumulus, that form in the early afternoon hours at the top of the atmospheric turbulent thermals (courtesy and credit: CESAR observatory at http://www.cesar-observatory.nl/). 


\section{What do we observe?}

This atmospheric turbulent boundary layer is very dynamic over time (Figure 7): it is relatively shallow, with a maximum of approximately 200 metres at night, but it grows rapidly during the night-day transition to reach almost 1500 metres at the end of the afternoon. The reason for these changes is that the main sources of turbulent energy, closely connected with processes occurring at the surface, have changed from the night and day. As the figure indicates, the complexity in the system is enhanced by the appearance of fair-weather clouds at the beginning of the afternoon that under certain atmospheric conditions may develop in heavy precipitation systems. My second dialogue is set.

My first option could have been to study all these turbulent dynamics and attempt to understand why turbulence changes during the day and behaves in such a way. Instead, I decide to cross disciplines and ask myself the following question:

What would happen if, instead of a nice summer with plenty of soil moisture, the conditions are characterised by a drought or heatwave situation in which our plants, in this particular case our grass field, are feeling these atmospheric and surface water stresses?

In order to properly understand this, we need first to move down several spatial scales to understand what is happening at the leaf, or even smaller scale. The plant is suffering stress and therefore closes its stomata. Just like us on a hot summer day at the beach, plants are keeping a low profile. Their leaves need to prioritise retaining and regulating their internal water, which means that this is not the best time for assimilating $\mathrm{CO}_{2}$. These are tough times to photosynthesize and grow.

\section{Where does the energy go which is not used for photosynthesis?}

The available energy received at the leaf surface from the sun is therefore shifted from photosynthesis/evaporation to warming the atmosphere. As a result, there is an intensification of the turbulent thermals and the final outcome is that turbulence will become more vigorous and the boundary layer will become deeper i.e. even more so than the observable 1500 metres mentioned earlier, a condition which may potentially modify the shape and organisation of the cloud intensity and populations.

But this is only one part of the story, the one that involves the small scales. Let's then move to the spatial scales larger than the atmospheric boundary layer. Since the day is clear, sea breezes will form due to the larger thermal differences between the warm land and the cold North Sea. The sea breeze reaches the Cabauw tower and disrupt our boundary layer turbulence, at a scale that is larger than the turbulent scale. In 
conclusion, if you wish to understand the dynamics of the atmospheric boundary layer at Cabauw or somewhere else around the world, we need to build a bridge between the small scales governed by the leaf dynamics and the large atmospheric scales driven by the sea breezes.

In closing this dialogue, I would like to merge it with the first one. In short, the challenge is therefore to first understand these biological, chemical and physical processes that occur on a wide range of scales. In doing so, we encompass from the continuous movements of the tiny stomata as they respond to all sorts of atmospheric perturbations to the much larger-scale sea breeze formation. Between these extremes, turbulent scales lie. Let's not forget that all of these mechanisms and relatively short scales are strongly modulated by weather variability, such as we see on the TV weather forecast every night, and are characterized by low and high-pressure systems, and the changes that occur year by year in our climate.

This understanding of processes and scales is fundamental to improve models that enable us to calculate and forecast for weather, air pollution levels and climate.

\section{But, how can we represent them and make forecasts?}

How can we integrate and embed all these scales and all these processes? or

\section{How can I merge my dialogues 1 and 2?}

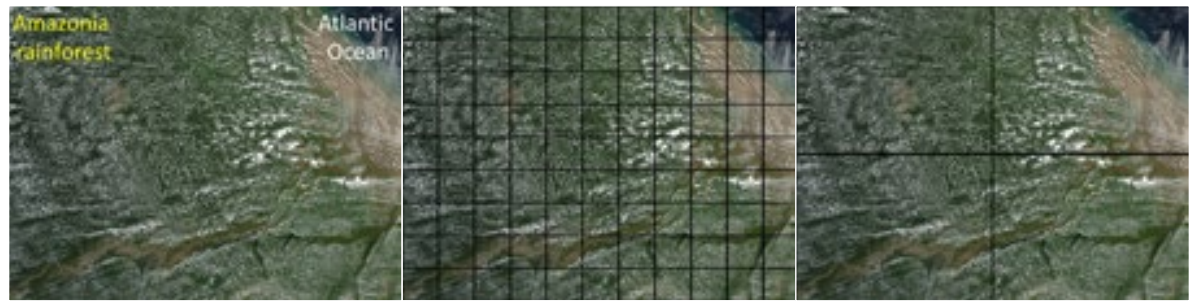

Figure 8. The Amazonian rainforest and Atlantic Ocean (left panel) discretized using representative grid resolution in numerical weather prediction models, $\sim 2$ to $5 \mathrm{~km}$, (centre panel) and global climate carbon models, $\sim 50 \mathrm{~km}$ (right panel).

Let's go back to Amazonia, and more specifically to the Amazonia delta where the tropical rainforest merges with the Atlantic Ocean. Our current ability to calculate the meteorological variables is limited by computing capacity and the wide range of relevant scales in the biosphere-atmosphere system. On the one hand, on the larger scales, we need to describe all the Amazonia basin processes including the important 
climate influences of phenomena like el Niño, but we don't want to miss all the details related to the biosphere and atmosphere interaction. We need to make choices.

As I have already mentioned, our current prognostic weather calculations are limited by our computing capacity. The highest grid spatial resolution today in a numerical weather forecast model is $2 \times 2 \mathrm{~km}^{2}$ (Figure 8 centre). If we solved the weather governing equations at higher resolution (below $2 \times 2 \mathrm{~km}^{2}$ ), we are not able to forecast the weather in advance and our weather prognosis will be too late. For the climate scenario projections, the model grid resolution is even coarser and greater than $50 \times 50 \mathrm{~km}^{2}$ (Figure 8 right).

We therefore miss the atmospheric phenomena that occurs on smaller scales: in our example of $2 \mathrm{~km}$ for weather or $50 \mathrm{~km}$ for climate. In short, unless we do something, we are omitting the role of small spatiotemporal scales or the processes occurring at the sub-grid levels. Just to refresh your memory, these processes are (among them): plant transpiration, formation of aerosols, turbulence and the initial stages of cloud formations.

In order to take these processes into account, we need to represent them in our weather and climate models by mathematical expressions that represent reasonable approximations to reality. In our scientific jargon, we call these parameterisations of the sub-grid phenomena.

Until now, the parametrisations of turbulence, clouds, or the closing/opening stomata have mainly been derived and studied in isolation. In other words, little attention was paid to the role of interactions between biological, chemical and physical processes, and how they interact on different scales.

\section{At this point, I am able to formulate our science mission strongly connected with a} suitable methodology. Our current and future research lines aim to investigate these aspects of the land and atmosphere interaction by moving ahead and becoming more interdisciplinary, in order to integrate processes and connect them up the different scales.

Let me show you how we are doing this. In our sequential images of Amazonia (Figure 3), we saw that the system is very dynamic, with continual changes of light use levels and turbulent intensities due to never-ending passing of clouds with very different characteristics. These clouds strongly modulate the rates of evaporation and atmospheric warming. In order to develop physically and biologically sound 
parameterisations of these sub-grid phenomena, we need first to understand the fundamentals of the processes and their interactions. In other words: we need to simulate these processes as accurately and as explicit as possible and under a wide range of conditions.

We do this first by virtually reproducing the processes, using numerical simulation tools that can approach a high degree of detail and explicitly solve turbulence, clouds and their interactions with the surface, mainly vegetation canopy and soil (Sikma et al., 2017).
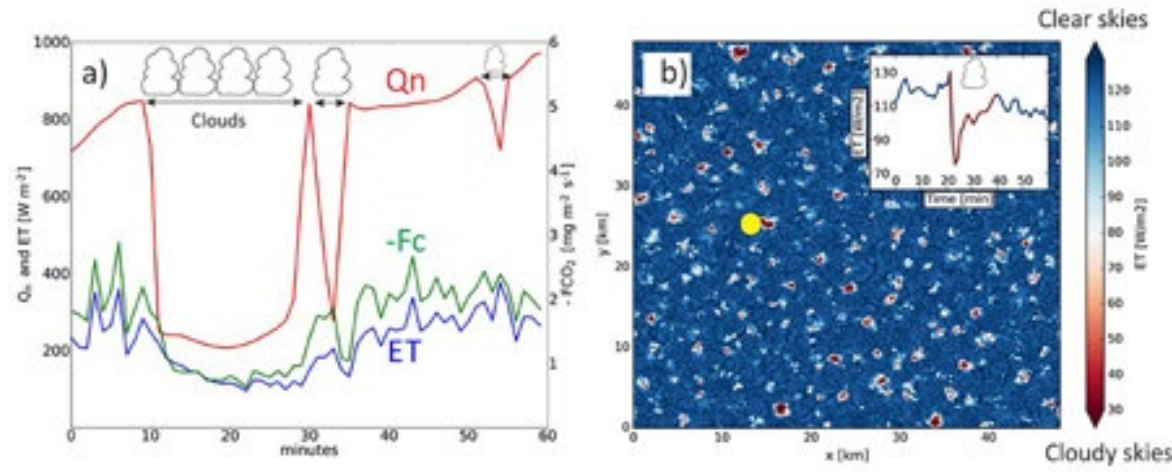

Figure 9. Two new methods used to study the coupling between vegetation and clouds. (a) Observations: one-minute averaged observations of available net radiation ( $Q n)$, evapotranspiration $(E T)$ and net carbon flux $(F c)$ influenced by the passage of a cloud as measured by the scintillometer technique and $(b)$ LES simulations: spatial plant-evaporation distribution influenced by shallow-cumulus clouds simulated at an horizonatl $50 \mathrm{~m}$ resolution on a domain of $48 \times 48 \mathrm{~km} 2$, and vertical resolution 12.5 metres. Lower values of ET (red) are caused by cloud shading. Inset figure shows evapotranspiration evolution at a virtual station site marked by the yellow point (red line, starting at 20 min, marks a decrease on evapotranspiration during the passage of a cloud similar to Figure 3).

We are now in a position to simulate the coupling between responses of vegetation and atmospheric turbulent fluctuations including the impact of cloud variability, mimicking Figure 3. The simulation, some sort of virtual reality, that I show in Figure $9 \mathrm{~b}$ reproduces the passage of clouds and how plant stomata responds to different intensities of cloud shading by opening and closing. As a result of the stomatal closing, plant transpires less and evapotranspiration decreases (red regions in Figure 9b). This response leads to a strong spatiotemporal variation on evapotranspiration and therefore large changes in the surface energy balance. The simulation represents a typical summer day in the Netherlands, with the presence of moving fair-weather clouds. 
These are research results based on high-resolution numerical experiments, namely the Dutch Atmospheric Large-Eddy Simulation (DALES, https://github.com/dalesteam/, see Heus et al. (2010) for more information). The scientific method requires us to contrast, to constrain and to validate such simulations by using other methods. At the Meteorology and Air Quality Section, our leading group of experimentalists are able to measure from the leaf level to the cloud scale using novel instrumental techniques, as shown in Figure 9a (van Kesteren et al., 2013). Similar to the numerical example that I have shown before, they are able to measure how plant evapotranspiration and $\mathrm{CO}_{2}$ assimilation respond to the rapid passage of clouds. Such observations, with an unprecedented level of detail and accuracy, enable us to learn how atmospheric conditions influence plant $\mathrm{CO}_{2}$ uptake and water loss.

In summary, our ability to mimic the interactions between vegetation and clouds at such level of numerical detail and to gather highly-specialized measurements to complete this research, places the Meteorology and Air Quality Section in a unique position to investigate the coupling between the biosphere and atmosphere and give us an unprecedented level of synergy to accept new research challenges.

We are now in a position to start to answer a wide range of questions and obtain the answers by analysing our numerical experiments and field observations. Challenging questions are now:

1 Linking biology and physics: How strong and relevant is the coupling between vegetation (grass, forests and crops) and clouds?

2 Linking biology, chemistry and physics: Does vegetation promote the emission of biogenic volatile compounds in order to create improved atmospheric and cloud conditions for plants?

3 Connecting with extreme weather: Does the vegetation-cloud system react in a similar manner under drought and heatwave conditions comparable to those experienced in Europe 2003, Russia 2010 and Amazonia 2010? Are local biosphere conditions enhancing or preventing drought or heatwaves? How do they interact with regional or continental-scale processes and responses?

4 Connecting with the climate perspective: How will this interactive cloudvegetation system perform under the projected warmer and enhanced high $\mathrm{CO}_{2}$ concentrations?

These are key questions in which the small spatial and temporal scales associated with the biosphere and atmosphere interaction matter.

Before I draw these two dialogues to a close, let us look briefly into the past for inspiration and guidance. I would humbly like to relate all of these research questions to the work of early scientists. 


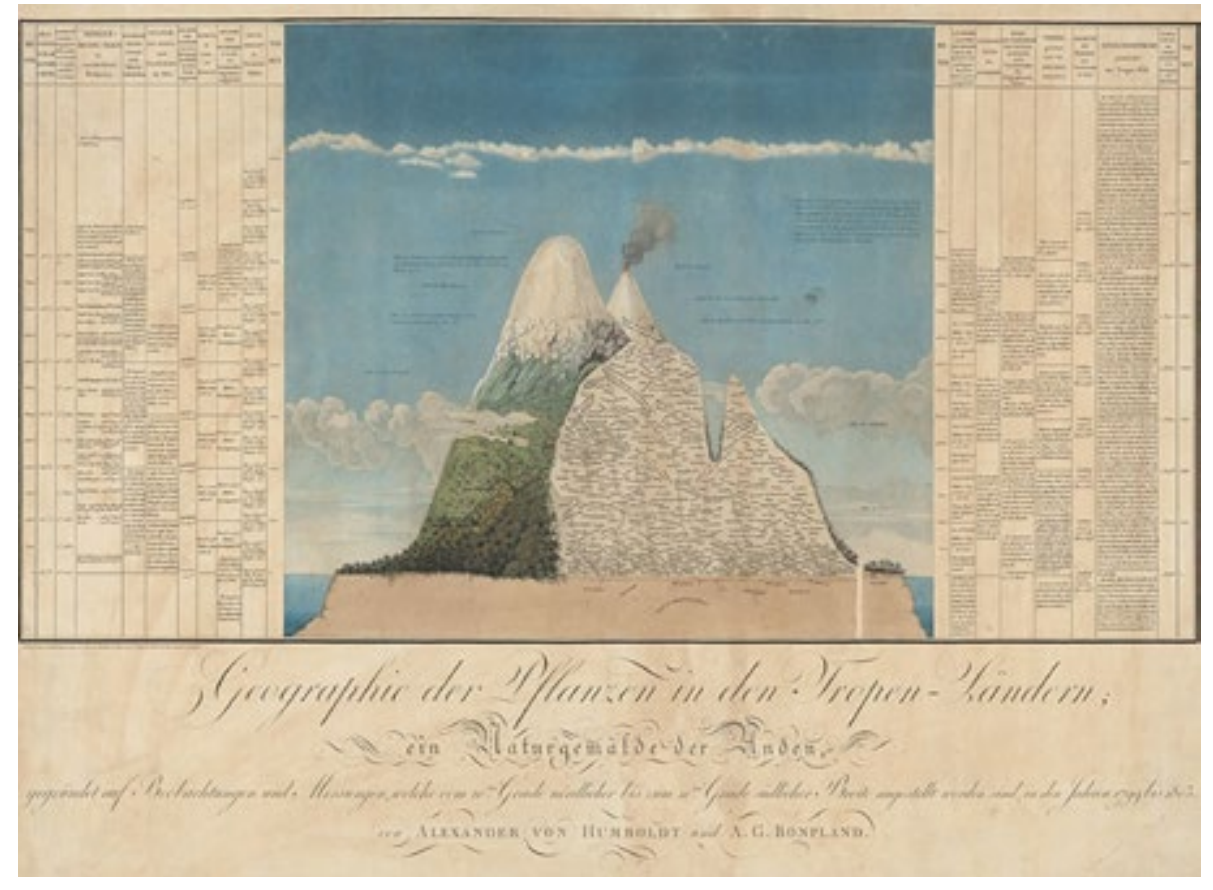

Figure 10. Naturgemälde (Nature Painting) of the volcano Chimborazo in Ecuador drawn and composed by the German scientist Alexander von Humboldt (1769-1859). It presents the location of the plants with altitude.

In 1802, after an inspiring climb to the volcano Chimborazo in Ecuador, Alexander von Humboldt made this scientific drawing (Figure 10), which he called in German Naturgemälde. Difficult to translate, it means a 'painting in nature', while implying a sense of wholeness (von Humboldt and Bonpland, 1807 and 2010). While he was climbing, he made all sorts of systematic meteorological observations and noted soil and vegetation characteristics according to their altitudes. He was the first scientist to relate atmospheric conditions to vegetation, and he too depicted all their variety and richness simply and in a coherent manner that paved the way for modern understating of ecosystems (Wulf, 2016).

The second historical scientific development is much more recent, as it dates from the year nineteen seventies, and was proposed by James Lovelock and Lynn Margulis (Lovelock and Margulis, 1974): the Gaia hypothesis, which suggests that planet Earth is a self-regulating system in equilibrium that helps to maintain life. Any disturbances of biochemical and physical processes can perturb this equilibrium and bring us to a new one characterized by different conditions of biology, chemistry and physics. 
Although these findings have been updated and you may agree or disagree with the hypothesis, they can still act as a source of inspiration. They help us to locate our current and future research within a broader context.

However, our ultimate goal at MAQ is to understand the atmosphere-biosphere system and to transfer this understanding to numerical models that will help us to better predict the weather and climate, and thereby greatly improve our capacity in forecasting:

the air that we breathe

the food that we eat

the energy that we use!

\section{Dialogue 3: Research versus education}

Let us start my third dialogue set by these two questions:

Should we keep all this scientific knowledge at the most advance level of highest research?

or

Should we transfer it?

and if so,

How do we transfer all these bits of knowledge and methods?

To frame this dialogue, I need to mention first that in my opinion, the universities play a unique role in society in that they ensure a proper transfer of scientific results by training new professionals for academia, more applications-oriented institutions and the private sector.

My third dialogue deals with how to conciliate upfront research with education at all levels. In my opinion, we still need to find a balance between encouraging the driving curiosity of the future scientists - namely, our students - and society's demands for concrete answers and strategies to tackle the current challenges associated to weather, air quality and climate.

I will mainly focus on how to do this transference properly, under current conditions characterized by pressure on budgets, and performing this job with the financial independence from funding agencies that allow us to be creative and not limited in our aspirations. 
Allow me to give you an example of how leading-edge research and education can be reconciled. It is based on my own experience.

It took eight years and a team formed by four people to create a new concept regarding how to transfer the scientific knowledge acquired on the interactions between the biosphere and atmosphere to students with different disciplinary backgrounds and levels of education. This educational method is called CLASS (Vilà Guerau de Arellano et al, 2015). In short, it consists of:

- a very flexible software package,

- a book that includes the fundamental concepts of these fields,

- and a set of hands-on exercise.

This material is complemented with a set of instructional and knowledge clips, and a complete set of numerical exercises with all related information grouped on a web page.

Although at the time we did not have the foggiest idea that similar educational methods had been developed in other fields, CLASS is close to the concept of the flipped classroom, as it is known by educational specialists.

According to Wikipedia:

In a flipped classroom, students watch online lectures, collaborate in online discussions, or carry out research at home and engage in concepts in the classroom with the guidance of a mentor.

As the definition mentions, the educational method aims to activate the student in his/her learning process and thus assimilate better and more rapidly the fundamental concepts and their applications.

Since this is officially a lecture, I would like to employ and apply the concept of the flipped classroom here. For the next minutes, we will all be learning by doing, or to be even closer with the current younger generation, learning by gaming. I set the challenge.

In the next minutes let's do it with a practical and short example involving the audience!! It is inspired by my dialogues 1 and 2 ! 
Let us move to the future, more concretely, to 2100. We are still in Wageningen. It is a hot summer day. Due to the climate change, it is on average 4 degrees warmer than it was 73-years ago. At the same time, our measurements at Veenkampen, the official meteorological station at Wageningen still being funded by the University I hope, is recording levels of carbon dioxide around $750 \mathrm{ppm}$.

My research question, driven by my curiosity and I hope also yours, is the following: I would like to know how evaporation driven by grass is responding to these new conditions: warming of the planet Earth and enhanced $\mathrm{CO}_{2}$ levels. I perform my first experiment under present 2017 conditions.

\section{Summer day: Evaporation today}

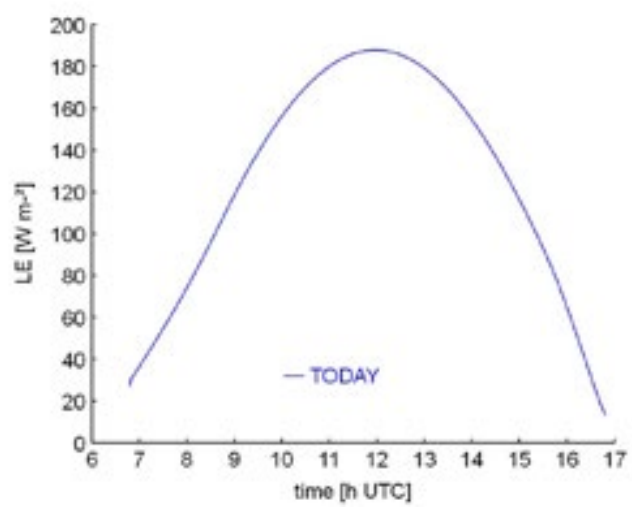

Figure 11 Temporal evolution of the surface evaporation calculated using the model CLASS. The initial and boundary conditions are inspired in a typical summer day at the Cabauw tower under PRESENT global temperature $(288 \mathrm{~K})$ and carbon dioxide concentrations (40o ppm). Local time is UTC +2 hours.

This is my diurnal evolution of evaporation. What Figure 11 is telling us is that the surface covered mainly by grass is losing water by evaporation. On a back-of-theenvelope calculation, in the 10 hours of sunshine, through the grass the biosphere has lost approximately $4.5 \mathrm{~mm}$ of water.

I set with CLASS two futuristic experiments to compare the future with today's conditions. In other words, I reproduce the diurnal variation in evaporation under the 2100 conditions. I do this step by step in order to break down the complexity of the system. I first introduce and explain the experiments. Please pay attention, because you will need to choose one option. 
Future experiment \#1. I will call this BIOLOGY driven. This future atmosphere is characterized by $\mathrm{CO}_{2}$ concentrations that are higher than under current conditions. Plants are lazy, since there is plenty of food (carbon dioxide) to perform photosynthesis and to produce the necessary sugars. In climate jargon, this situation is called $\mathrm{CO}_{2}$ fertilization. The consequence is that, at leaf level, the stomatal apertures are more closed than they are today and, as a result less water, is lost by the plant. We therefore expect that evaporation should decrease.

Future experiment \#2. I will call this PHYSICS driven. Due also to the rise in the greenhouse gas emissions, and the consequent effect of the trapping of radiation, the atmosphere has become warmer. As a result, the atmosphere has an enhanced capacity to take up water and is demanding that plants should evaporate more. We therefore expect that evaporation should increase.

Let's see now the physical and biological intuition of this very heterogeneous classroom. Let's take the pulse of this knowledgeable audience:

- Who thinks that BIOLOGY effects will be dominant compare to the PHYSICS effect? Please raise your hands,

- Who thinks that PHYSICS effect will be dominant aspects compared to the BIOLOGICAL effect? Please raise your hands,

$9 \%$ increase evaporation

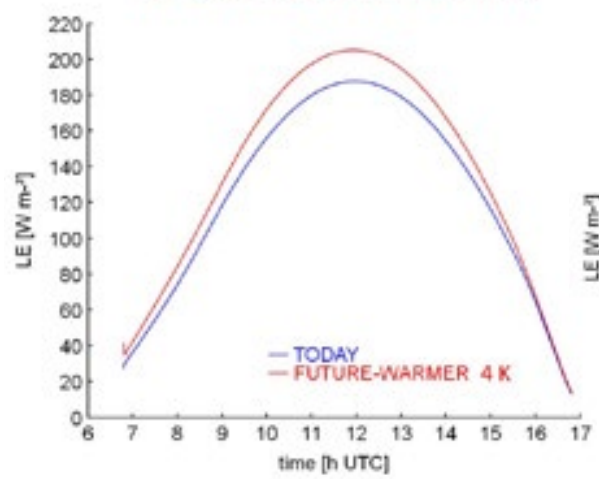

$13 \%$ decrease evaporation

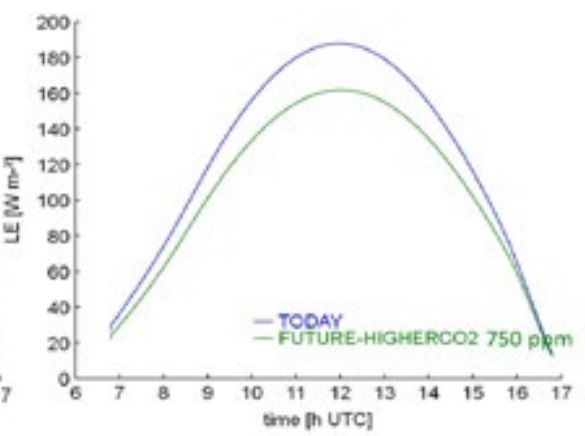

Figure 12 Temporal evolution of the surface evaporation calculated using the model CLASS under FUTURE conditions: global warmer conditions increased by $4 \mathrm{~K}(292 \mathrm{~K})$ and global carbon dioxide concentrations conditions increased by 250 ppm (650 ppm). Local time at Cabauw is UTC +2 hours. 
Both effects lead to similar increases (for the physically driven experiment see Figure 12 left) or decreases (for the biologically driven experiment see Figure 12 right). This already indicates how subtle the biosphere and atmosphere interactions are.

Now, in our last experiment, we will combine the conditions of a warming atmosphere and an enhanced $\mathrm{CO}_{2}$ atmosphere. This is the overall effect. If we combine these two effects, we find that in this specific case, the biological effect dominates and leads to a decrease in plant evaporation during this futuristic summer day in Wageningen 2100 (Figure 13). We could further develop the analysis, but it will require some extra time, so feel free to go to the CLASS web page and play (http://classmodel.github.io/)!!!!

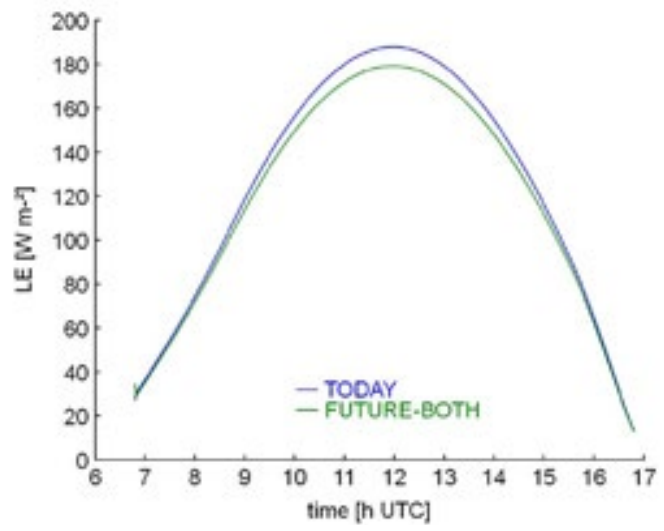

Figure 13. Temporal evolution of the surface evaporation calculated using the model CLASS. The initial and boundary conditions are inspired in a typical summer day at the tower Cabauw under PRESENT global temperature and carbon dioxide (blue) and FUTURE conditions driven by a warmer global conditions $(+4 \mathrm{~K})$ and enhanced carbon dioxide concentrations $(+350 \mathrm{ppm})$. Local time is UTC +2 hours.

\section{Thanks for your collaboration}

Though it seems now a simple exercise, the interpretation of these numerical systematic experiments enables us to connect our research to the students, and makes them understand the essentials concepts and couplings at the biosphere-atmosphere system, as well as the strong necessity to combine fields!

Although CLASS received limited financial support, the CLASS software and educational material are currently playing a crucial role in several courses at Wageningen University, in international lectures and in transferring the knowledge from leading-edge research to students and researchers with a wide range of backgrounds. 
At this point, I would like to mention the names of the core team of developers: Chiel van Heerwaarden, Bart van Stratum and Kees van den Dries, with fundamental theoretical and numerical contributions made by Huug Ouwersloot, Joel Schröter, David Pino, and Eduardo Barbaro. Arnold Moene coordinated the translation of CLASS to high-school level and Miranda Braam played a key role in producing the clips. We should not forget the many students who have acted as guinea pigs finding all sort of bugs and inconsistencies, and providing very accurate and essential feedback.

To conclude, team work at its best!!

Only possible in the dynamic and inspiring atmosphere provided by a first-class university such as Wageningen.

Viewing at a broader perspective, I believe universities in the Netherlands are making a very large effort, and with success, to adapt to new times, designing and developing new methods to better connect education with research. However, I believe it is not desirable that universities move towards private company structures, and therefore being obliged to seek for own complete financial funding. In $m \boldsymbol{y}$ opinion, universities will always remain a short-term cost that give long-term social and economic gains.

\section{Dialogue 4: School-thinking versus free-thinking}

It is almost time to close, which I will do with my fourth dialogue, entitled scholar thinking versus free thinking, and I will take this opportunity to acknowledge people and institutions. Let us move now to the past: Barcelona 1973. Spain has been ruled by a dictatorship for almost 40 years. I am 11-years old and I hardly noticed anything since I am attending a very liberal, democratic and secular elementary school. The dictatorship had some control gaps, like my elementary school, though it was still ruthless in carrying out dead executions for political reasons up until 1975.

My father is delivering an opening speech in the Academia of Bones Lletres Academy of Belles Lettres (Figure 14)- in the Gothic Quarter in Barcelona, an academic institution that opened its doors in 1700 to freely discuss philosophy, literature and history. If you go to Barcelona, drop by this Roman-Gothic building. It is worth a visit and you will not find a single tourist there. 


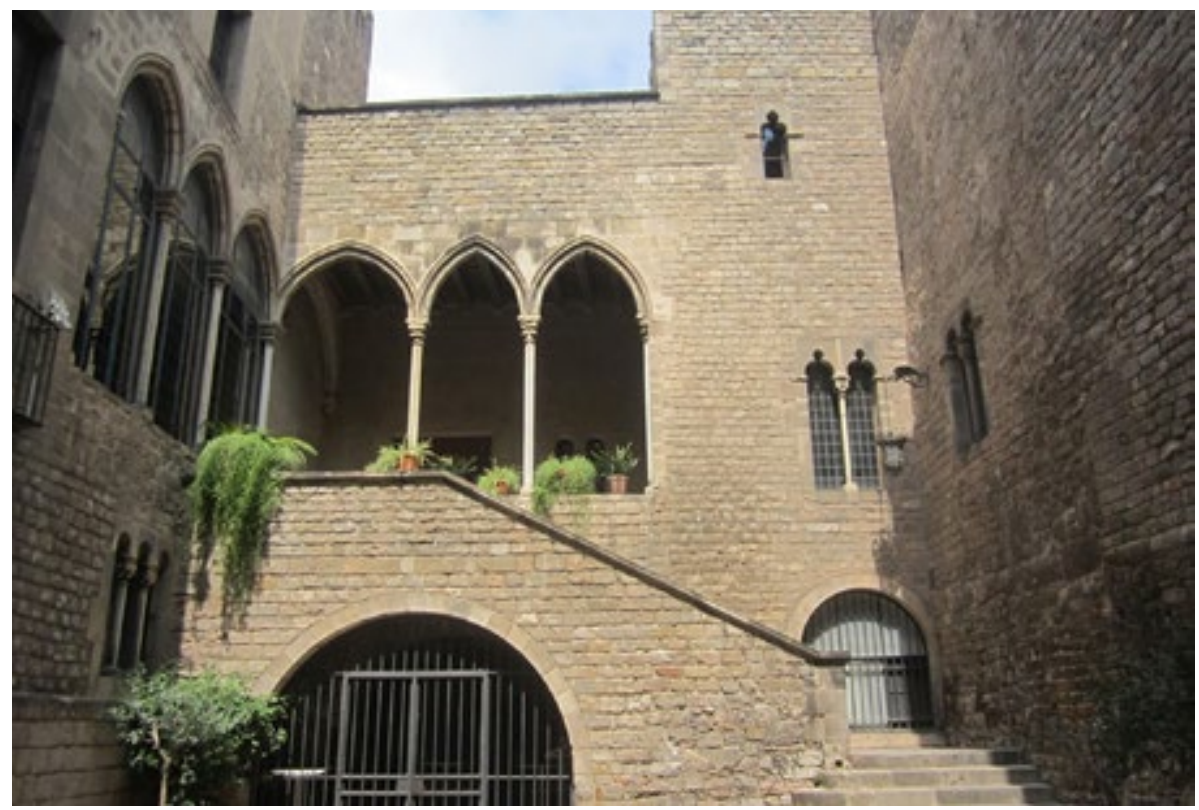

Figure 14. Main entrance and yard of the "Palau de Requesens" at the Gothic quarter in Barcelona and built in between the XIII and XV centuries. This is the official building of the Reial Acadèmia de Bones LLetres founded in 1752. More information at http://www.boneslletres.cat/.

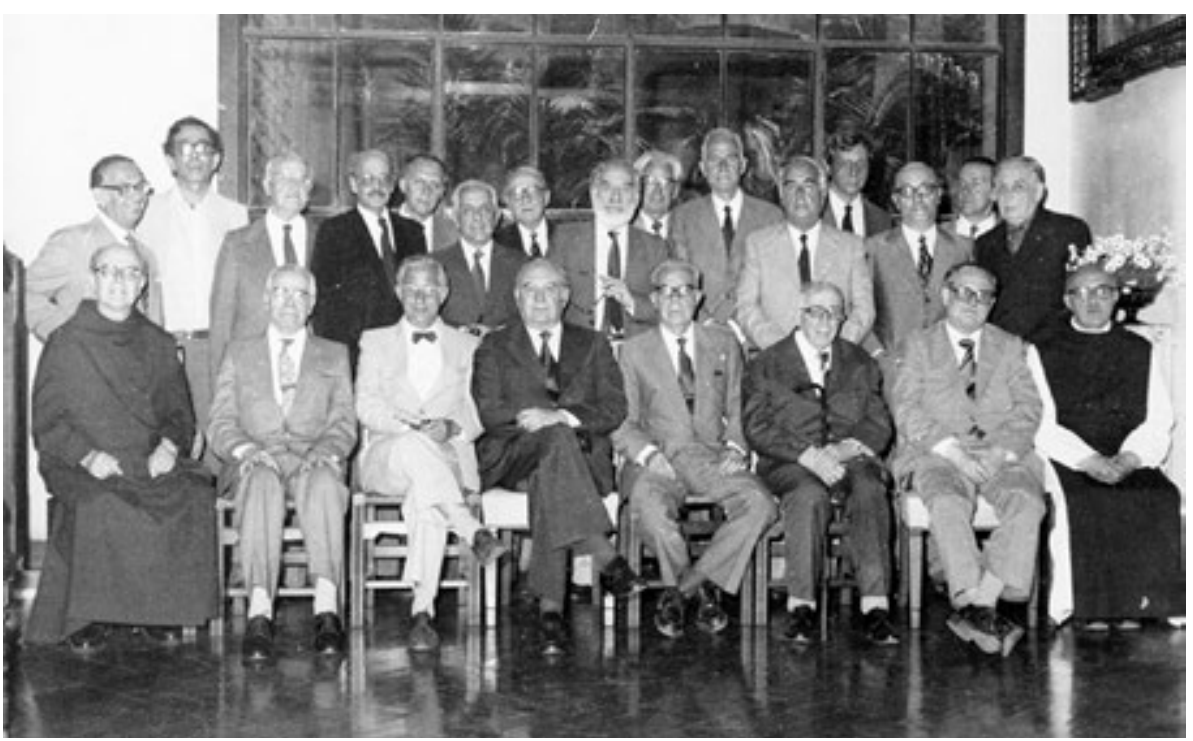

Figure 15 Members of the Reial Acadèmia de Bones LLetres in 1982. My father is standing (second right). 
My sister Marta and I are attending his opening speech. I can tell you a secret that I have long shared with her: without doubt it was not one of the more exciting moments of our lives. Time was literally not moving and I have never seen so many old people in my entire life (Figure 15). Still, and this is very relevant for this dialogue, I strongly sensed that something important was happening and that people with different disciplinary backgrounds were freely discussing things in spite of the severe constraint imposed by the political situation. They were part of a way of doing things ('a manière de faire') that creates a school of thinking. Please retain this concept of school of thinking, I will come back to it very soon.

Let's stay in the same year. As you can imagine, my thoughts were somewhere else completely. To be honest with you, I have wished that my father was in this next picture (Figure 16).

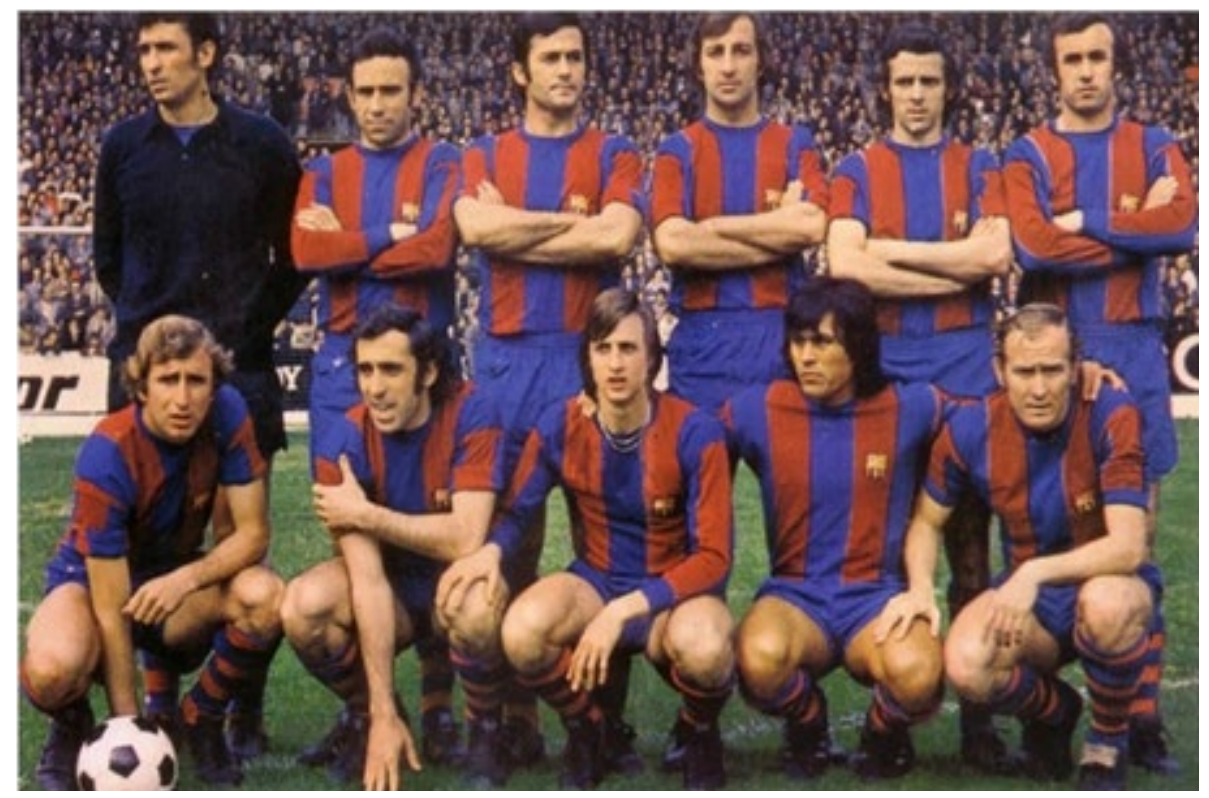

Figure 16. FC Barcelona official team during the season 1973-74. First row: Rexach, Asensi, Cruijff, Sotil and Marcial. Second row (standing): Sadurni, Rife, Torres, Costas, Juan Carlos, de La Cruz.

I hope you will recognize this centre forward. Now, you will ask yourself, why, in a serious academic ceremony am I showing this picture. The reason is simple. For an 11-year-old living in a controlled media country, it was shocking the way this centre forward was talking and behaving. No restrictions at all. He was saying what he was thinking. This guy was a free-thinker and he was the product of a free-thinking 
society. We take free-thinking for granted, but it is a precious and essential component of education and research. Without this capacity, we are unable to advance either scientifically or as a society. Let's not take it for granted! This free thinking is capable of organising and creating coherent ways of doing science, characterized by manners of reasoning, research aims and methodologies. Allow me to call this; thinking within a school.

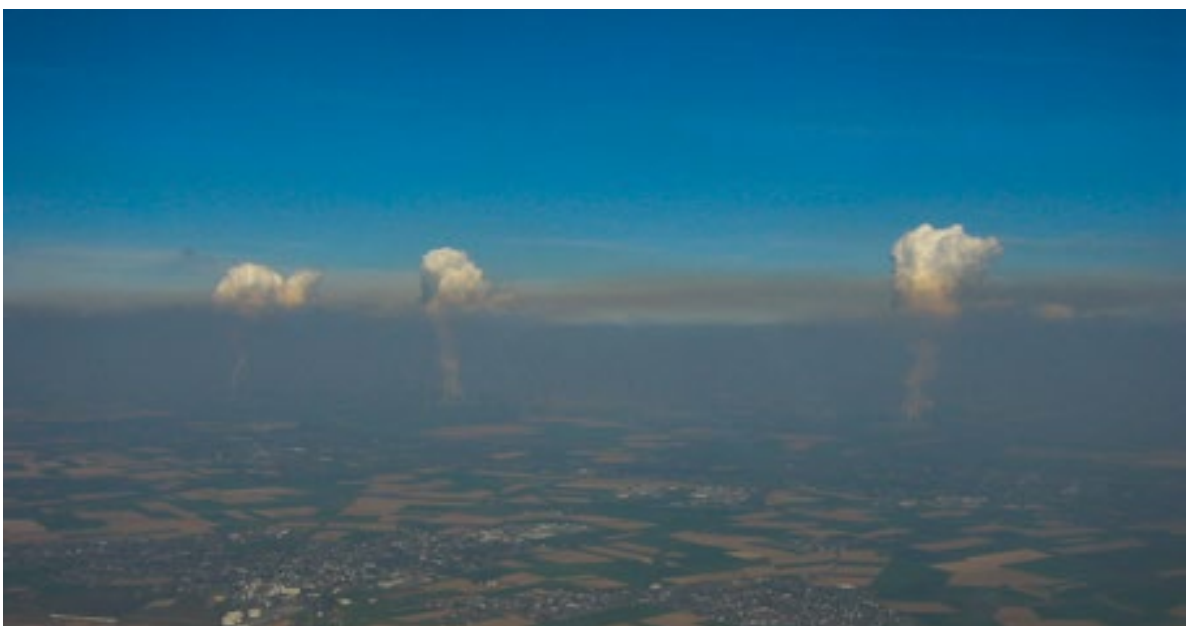

Figure 17. The atmospheric boundary layer in between the biosphere and the free atmosphere. This layer studied for more than 50 years by the Dutch Atmospheric Boundary Layer school in theoretical, observational and numerical research studies. It is a key component of the weather, atmospheric composition and climate. Courtesy and credit: Bart van Stratum.

In 1989, when I arrived in the Netherlands to do my PhD, I was confronted by a school of this sorts: the Dutch Atmospheric Boundary Layer School (Figure 17). It is mission impossible to define in a few words the philosophy of this school, but I will give it a try:

\section{Let us identify the essential elements of atmospheric processes in the lower} atmosphere, without losing the physical insight, and aiming to obtain a deeper understanding and more accurate representations of the atmospheric boundary layer in weather and climate models.

From theoretical and numerical studies, and observational data treatment analysis I was continuously confronted by outstanding research conducted by names like Tennekes, Driedonks, de Bruin, van Ulden, van Dop, Nieuwstadt, Beljaars, Bosveld, Holtslag, Tjemkes, Siebesma, Jonker and Duynkerke. 
Peter Duynkerke deserves a special thanks. Wherever you are, you made me a researcher.

I also am very glad to see that this school continues at full power with new fresh blood and ideas.

It took me a while to realise its relevance, after I arrived at Wageningen University, but then I also become acquainted with a similar school, but this one related to plant aspects. These were specialists in translating the complexity of plant physiology to mathematical representations, and more specifically to meteorology. Though I am still a bit behind them in their literature, models and findings, I am in debt to the Wageningen Plant Physiology/Meteorology school that strongly inspired and influenced by the seminal research of Goudriaan, includes the following names Jacobs and Jacobs, Heusinkveld, Hartogensis, Moene and Ronda.

My periodic visits to Max Planck Institute Chemistry at Mainz and the conversation with Jos Lelieveld, starting in a particular critical moment of my career, helped me to maintain contact with the experimental part of atmospheric chemistry!

Still at the academia. If I have something very clear in mind that I don't doubt for a single minute it is: I would not be here without the incessant work and feedback of MSc students and PhD's. I very often get comments that I am devoting too much time to advising students. My answer is always the same: it simply pays off. Supervising is a way of transferring a way of doing science, and in my opinion it is fundamental to the advancement of all sciences. At the same time, I have learned and I am learning a lot from the students. I don't have time to mention all the names of the more than $40 \mathrm{MSc}$ (thanks to all of you) that I have supervised, but I would like to name the PhDs: Stefano, Alessandro, Monica, Pau, Chiel, Ruud, Huug, Eduardo, Marie, Meto and the future ones Jon, Thomas, Martin, Xabi and Felipe. Many thanks! Finally, moving beyond science, this inaugural lecture is dedicated to my mother and to Reinhilde. It is not an easy task to live with a scientist! But everything for science!

To Quim and Isaac, I fully agree with you. This lecture has been extremely long and boring. Next time Anem al Camp Nou!

\section{Para los castellano hablantes: He dicho! Pels de parla catalana: He dit! \\ For the English-speakers: I have spoken! \\ Voor de Nederlanders: Ik heb gezegd!}




\section{References}

Andreae M. O. et al. (2015) The Amazon Tall Tower Observatory (ATTO: overview of pilot measurements on ecosystem ecology, meteorology, trace gases and aerosol. Atmospheric Chemistry and Physics 15, 10723-10776.

Apituley A. et al. (2008) Overview of research and networking with ground base remote sensing for atmospheric profiling at the Cabauw experimental site for atmospheric research (CESAR)-The Netherlands. IEEE Geoscience and Remote Sensing Symposium.

Da Vinci, L. (1517) Codex Atlanticus. XII volumes. Biblioteca Ambrosiana, Milan, Italy.

Heus T. (2010) Formulation of the Dutch Atmospheric Large-Eddy Simulation (DALES) and overview of its application. Geoscientific Model Development 3, 415-444

von Humboldt A. and Bonpland A. $(1807,2010)$ Essay on the Geography by plants. The University Chicago Press, pp 280.

van Kesteren B. et al. (2013) Measuring $\mathrm{H}_{2} \mathrm{O}$ and $\mathrm{CO}_{2}$ fluxes at field scales with scintillometry: Part II-Validation and application of 1-min flux estimates. Agricultural Forest Meteorology 178, 88-105.

Lovelock J. E. and Margulis L. (1974) Atmosphere homeostasis by and for the biosphere: the Gaia Hypothesis. Tellus Series A 26, 2-10.

Sikma M. et al. (2017) Interactions between vegetation, atmospheric turbulence and clouds under a wide range of background wind conditions. Agricultural and Forest Meteorology (on line).

Stull R. B. (1988) An introduction to boundary layer meteorology. Kluwer Academic Publishers, pp 666.

Vilà-Guerau de Arellano J. et al. (2015) Atmospheric Boundary Layer: Integrating Air Chemistry and Land Interactions. Cambridge University Press, pp 265.

Wulf A. (2015) The invention of Nature. John Murray publishers, pp 473. 



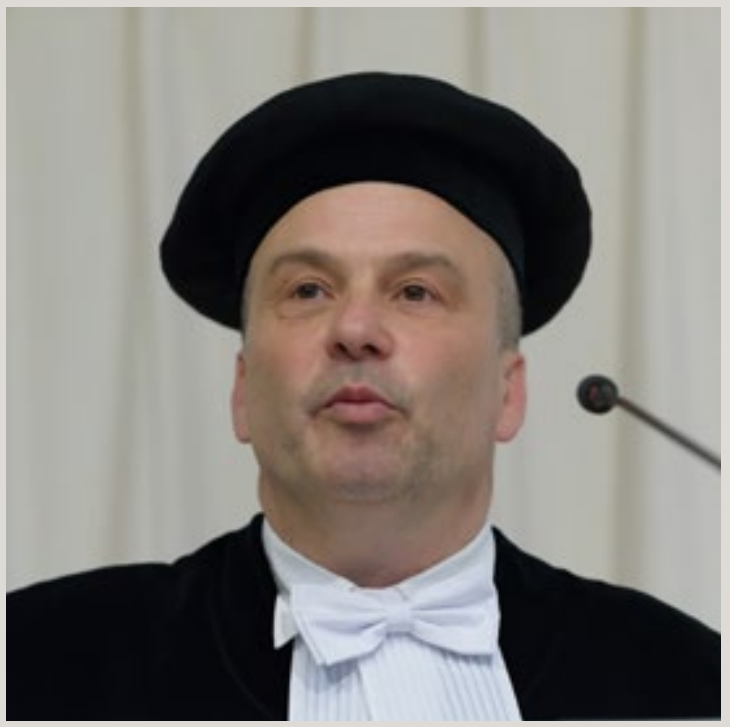

Prof.dr Jordi Vilà-Guerau de Arellano

'In this inaugural lecture, inspired by the integrating capacity of the atmospheric boundary layer, I discuss the need to understand the interactions between the biological and chemical processes that occur over land and their coupling with turbulence and cloud cycling. The challenge ahead lies in how to represent these small spatiotemporal interactions in weather and climate models. Taking advantage of the particular liberties conceded by an inaugural lecture, I challenge the audience to actively participate in this process of understanding and representing these crucial components of our Earth system.' 